\title{
Educação CTS e a não neutralidade da ciência-tecnologia: um olhar para práticas educativas centradas na questão energética
}

Suiane Ewerling da Rosa suiedr@gmail.com

0000-0001-6476-9386

Universidade Federal do Oeste da

Bahia, Barreiras, Bahia

Universidade de Brasília, Brasília

Roseline Beatriz Strieder roseline.unb@gmail.com 0000-0001-8965-8906

Universidade de Brasília, Brasília

\begin{abstract}
RESUMO
Este trabalho busca verbalizar dimensões silenciadas e associadas à suposta neutralidade a fim de contribuir com a elaboração de práticas educativas. Constituído de uma pesquisa bibliográfica, o corpus de análise foi formado por artigos, autoidentificados por práticas educativas CTS centradas na questão energética. Para a obtenção dos resultados utilizamos a Análise Textual Discursiva, que resultou nas seguintes categorias mistas, oriundas de um desdobramento teórico-prático de práticas educativas CTS e elementos da abordagem temática freireana: seleção e natureza dos temas; elaboração das problematizações; papel e seleção dos conhecimentos; e, postura dialógica e participativa. Dentre os resultados, destacamos indicativos de práticas que verbalizam dimensões silenciadas e propiciam atividades e ações participativas em sala de aula. Além disso, ressaltamos a importância de abordar problemas reais e contradições sociais, que possibilitam problematizar conhecimentos e vozes além dos técnico-científicos, contribuindo para a superação de visões ingênuas e a construção de processos democráticos.
\end{abstract}

PALAVRAS-CHAVE: Educação CTS. Não neutralidade da ciência e tecnologia. Práticas educativas. 


\section{INTRODUÇÃO}

A disseminação da educação Ciência-Tecnologia-Sociedade ${ }^{1}$ (CTS) em práticas educativas vem crescendo no Ensino de Ciências no contexto brasileiro (FREITAS; GHEDIN, 2015; STRIEDER; BRAVO; GIL QUILEZ, 2017). Associado a isso, diferentes trabalhos do tipo estado da arte vêm sendo realizados, evidenciando, cada vez mais, a necessidade de um olhar crítico sobre essas propostas. Dentre esses trabalhos, destacamos os realizados por Autor (2014) e Autores (2016) que identificam, em práticas educativas desenvolvidas no Brasil, formas de silenciamentos ou ausências de dimensões que problematizem a suposta neutralidade da Ciência e Tecnologia. De acordo com esses autores, essas omissões podem fragilizar processos democráticos em tema sociais de Ciência e Tecnologia, um dos objetivos centrais do movimento CTS.

Dando continuidade aos trabalhos citados, o objetivo deste artigo é propor sinalizações que podem contribuir para que práticas educativas verbalizem dimensões associadas a não neutralidade da Ciência e Tecnologia. Isso perpassa por reconhecer os silenciamentos e por superar compreensões que alimentam concepções ingênuas. Além disso, é preciso articular esses discursos ao contexto educacional, pensando em termos do planejamento e desenvolvimento de práticas educativas. Esses processos, que envolvem a escolha dos temas e problemas, sua articulação aos conhecimentos a serem trabalhados, a definição das estratégias de ensino e a implementação da proposta em sala de aula, devem ser coerentes com o almejado no âmbito da educação CTS.

Dessa forma, como ponto de partida para esta investigação, consideramos os silenciamentos identificados nos trabalhos mencionados e reflexões oriundas da articulação Freire-CTS, em especial, as que estão relacionadas ao processo de elaboração e desenvolvimento de abordagens temáticas. Para exemplificar e contribuir com possíveis superações, analisamos artigos sobre CTS, publicados em revistas da área de Ensino de Ciências, no contexto brasileiro, que tenham como foco de discussão o tema "questões energéticas". A escolha por esse tema deu-se pelo fato de ser uma das propostas temáticas mais trabalhadas em práticas CTS no contexto brasileiro (STRIEDER; BRAVO; GIL QUILEZ, 2017), bem como, por evidenciar a potencialidade de discussões no âmbito das ciências naturais.

Assim, por meio da análise de trabalhos da área e fundamentado nos pressupostos da articulação Freire-CTS e do Pensamento Latino Americano em Ciência-Tecnologia-Sociedade (PLACTS), apontamos elementos que podem vir a orientar práticas educativas, os quais estão associados à i) Seleção e natureza dos temas; ii) Elaboração das problematizações; iii) Papel e seleção dos conhecimentos; e, iv) Postura: diálogo e participação. Destacamos que não entendemos esses elementos como algo que engessa as práticas e propostas curriculares, pelo contrário, são sinalizações orientadoras na busca por novos caminhos e alternativas para repensar nossas ações, com vistas à formação de cidadãos compromissados com uma sociedade mais justa e igualitária, aptos a participar de processos relacionados à Ciência e Tecnologia.

\section{A NÃO NEUTRALIDADE DA CIÊNCIA E TECNOLOGIA E OS SILENCIAMENTOS SOBRE A ATIVIDADE CIENTÍFICO-TECNOLÓGICA}


Apesar da educação CTS ser considerada um campo com diferentes abordagens, sua origem está relacionada a um movimento social mais amplo associado, dentre outras coisas, a um contexto de insatisfação de segmentos da sociedade diante da concepção linear/tradicional da relação entre Ciência e Tecnologia ${ }^{2}$. Esse contexto faz surgir, em meados do século $X X$, movimentos acadêmicos e sociais com o objetivo de reivindicar uma postura crítica diante de questões sociais, éticas, ambientais, econômicas, etc., relacionadas ao desenvolvimento científico-tecnológico (GARCÍA; CEREZO; LÓPEZ, 1996). Dentre esses movimentos, podemos destacar os que foram desenvolvidos na América do Norte, na Europa e na América Latina, cada um com pressupostos, motivações e repercussões diferenciados.

O movimento norte-americano esteve marcado pela preocupação das consequências socioambientais dos produtos tecnológicos, enquanto o europeu tinha como eixo central, descrever como a gênese e aceitação das teorias científicas são influenciadas pela diversidade de fatores valorativos (CEREZO, 1998). Na América Latina, o movimento tinha como gênese central, a problematização da política científico-tecnológica dos países dessa região, em especial, por ela estar estruturada a partir das necessidades de países do denominado Primeiro Mundo. Esse movimento é constituído pelo PLACTS, por intelectuais de diferentes áreas que defendem o redimensionamento da agenda de pesquisa latino-americana, que deve prezar e ser coerente com as demandas sociais vivenciadas pelos países dessa região (DAGNINO, 2003).

É válido destacar que independente da vertente, a repercussão dos movimentos se dá em um contexto no qual Ciência e Tecnologia são deslocadas do espaço da suposta neutralidade para o campo de debate político. A suposta neutralidade, como propõe Auler (2002) está associada a três mitos: determinismo tecnológico, salvacionismo científico-tecnológico e modelo de decisões tecnocráticas. $\mathrm{O}$ mito do determinismo é compreendido a partir de duas ideias centrais: i) a mudança tecnológica causa linearmente uma mudança social; e, ii) a tecnologia é autônoma, não opera por si mesma, sendo assim independente das influências sociais. A perspectiva salvacionista da Ciência e Tecnologia está atrelada ao modelo tradicional/linear de progresso. Nessa, Ciência e Tecnologia são criadas para solucionar os problemas da humanidade levando linearmente ao bem-estar social. E, referente ao modelo de decisões tecnocráticas, o autor destaca que a crença está na possibilidade de neutralizar/eliminar a sociedade do processo de decisões técnico-científicas. Nesse, apenas o especialista é capaz de solucionar todos os problemas, inclusive os sociais, de maneira ideologicamente neutra.

Embora a concepção de neutralidade seja, em linhas gerais, superada no domínio epistemológico e sociológico contemporâneo, ainda persiste em diferentes âmbitos, inclusive no contexto educacional (AUTOR, 2014). Entendendo que o discurso genérico de que Ciência e Tecnologia não são neutras, pouco contribui para um olhar crítico das suas interações, Autor (2014) realizou uma análise que buscou problematizar e situar discussões referentes à suposta neutralidade da Ciência e Tecnologia, tanto do ponto de vista teórico quanto empírico. Como resultado dessas análises, foram identificadas dimensões silenciadas em práticas educativas CTS as quais, caso não problematizadas, contribuem para sustentar compreensões próximas da suposta neutralidade. Essas dimensões associam-se (1) aos valores incorporados na origem/concepção e 
execução da Ciência e Tecnologia; (2) às dimensões de outras naturezas, além da científico-tecnológica, presentes em processos decisórios; e, (3) aos valores internalizados nos produtos científico-tecnológicos.

Silenciar sobre os valores presentes na origem/concepção e/ou execução da Ciência e Tecnologia sinaliza para compreensões próximas ao do determinismo tecnológico, sustentando, de alguma maneira, a suposta neutralidade. No determinismo, conforme já exposto, a tecnologia é entendida como um limitante das ações da sociedade (GÓMEZ, 1997), ou seja, nessa perspectiva, a sociedade não possui potencial para alterar a dinâmica do desenvolvimento científicotecnológico, mas apenas para recebê-lo. Portanto, omitir sobre dimensões relacionadas aos valores incorporados nas políticas públicas da Ciência e Tecnologia contribui, em linhas gerais, para potencializar a unidirecionalidade que vai da Ciência e Tecnologia para a sociedade. Assim, verbalizar influências mútuas entre desenvolvimento científico-tecnológico e sociedade identificando os valores presentes na concepção e execução da atividade científico-tecnológica, dá indicativos de superação do determinismo, abrindo a possibilidade de potencializar discussões voltadas para mecanismos ampliados de participação em processos de decisão.

Referente aos processos decisórios, destacamos que eles envolvem outras dimensões além das científicas e tecnológicas, a exemplo das econômicas e políticas. Essas dimensões, de outras naturezas, têm sido silenciadas e precisam ser verbalizadas. Portanto, é importante problematizar o modelo de decisão tecnocrática, no qual apenas o viés científico-tecnológico é considerado como condição necessária e suficiente para a compreensão e enfrentamento de problemas, inclusive os sociais. Ou seja, é preciso superar a percepção de que para cada problema há uma solução estritamente técnica, e, ainda, que a decisão é oriunda de um especialista supostamente neutro. Decisões políticas acompanham os processos técnicos, conforme destacado por Feenberg (2010) em um diálogo sobre a análise crítica da tecnologia: mesmo quando "[...] dispusermos de soluções puramente técnicas para um problema, então a escolha entre elas torna-se tanto técnica quanto política. As implicações políticas da escolha serão incorporadas à tecnologia" (p. 266).

Complementando essas discussões e referente ao terceiro silenciamento, tem-se a verbalização de que as questões valorativas não estão presentes apenas na participação nos rumos da atividade científico-tecnológica, conforme explicitado no primeiro silenciamento, mas também são incorporadas aos produtos da Ciência e Tecnologia. Para problematizarmos essa ideia, vamos considerar a compreensão - supostamente superada - de linearidade entre mais Ciência e Tecnologia e mais bem-estar social, identificada em Autor (2014). Esta superação, em alguns âmbitos, está articulada com a participação pós-produção (viés relacionado ao processo e avaliação dos impactos gerados pela Ciência e Tecnologia) que incorpora, na sua compreensão limitada, formas de silenciamentos. Destaca-se que a não linearidade, ou seja, impactos positivos e negativos da Ciência e Tecnologia, não decorre apenas da boa participação pósprodução, bom e mau uso, ideia muito comum na sociedade, mas também do fato de que o produto científico-tecnológico incorpora, internaliza, materializa valores e interesses. A verbalização dessa dimensão silenciada está relacionada às implicações da Ciência e Tecnologia. 
Assim, diante desses três silenciamentos identificados e problematizados, destacamos algumas sinalizações articuladas entre si, que precisam ser verbalizadas: i) a questão valorativa da Ciência e Tecnologia está presente em todo o processo, ou seja, inicia na definição das políticas públicas, na definição da agenda de pesquisa; ii) a participação pós-produção apesar de importante é limitante, isso porque ficar restrito apenas a esse mecanismo pode levar à ideia de que cabe à sociedade tirar o melhor proveito do produto científico-tecnológico; iii) algumas implicações oriundas do produto científico-tecnológico resultam não apenas do uso dado, mas também de possíveis interesses de quem a concebe; iv) conhecimento científico é necessário mas insuficiente para resolução de problemas sociais; v) decisões técnicas acompanham decisões políticas; e, vi) é necessário ampliar os atores envolvidos no processo de decisão em temas relacionados à área de Ciência e Tecnologia como superação das decisões tecnocráticas ditas neutras.

As discussões aqui explicitadas não esgotam as possibilidades de verbalizações de dimensões importantes dentro da perspectiva da superação da suposta neutralidade. Elas resultam de um levantamento teórico-empírico e proporcionam, dentre outras coisas, a realização de um exercício de reflexão e ação das nossas práticas educativas, que não podem ficar restritas a um discurso genérico e pouco crítico sobre as interações CTS. Diante disso, nos próximos itens iremos exercitar o domínio teórico-prático dessas dimensões, ou seja, como proporcionar possíveis verbalizações da não neutralidade da Ciência e Tecnologia em práticas educativas, o que, a nosso ver, pode ter como eixo estruturador a abordagem de temas fundamentada pela perspectiva Freire-CTS, como será discutido adiante.

\section{ABORDAGEM DE TEMAS NO ÂMBITO DA PERSPECTIVA FREIRE-CTS}

Segundo Aikenhead (2005) o movimento CTS repercutiu para o contexto da educação na década de 1970 e início de 1980, no momento em que se desenvolvia um amplo consenso entre educadores de Ciências com relação à necessidade de mudanças na área, em busca de uma educação política. Influenciados por isso, passaram a almejar práticas que efetivassem abordagens multidisciplinares, com currículos em torno de problemas reais, visando à democratização de processos decisórios.

Particularmente no que diz respeito ao contexto brasileiro, concordamos com Auler (2002) quando destaca que precisamos considerar a inexperiência democrática da sociedade como um obstáculo à democratização e, associado a isso, defendemos a articulação entre CTS e os pressupostos educacionais de Paulo Freire. A educação, segundo Freire (2005), deve contribuir para a compreensão crítica da realidade, possibilitando a superação da cultura do silêncio e de situações limites, caracterizadas como situações concretas entendidas pelos sujeitos em processo de libertação como intransponíveis e paralisantes.

Essas situações limites podem ser relacionadas às compreensões vinculadas à suposta neutralidade, considerando que elas dificultam a constituição de uma percepção crítica das relações CTS, limitando a participação da sociedade em 
pouco críticas sobre aspectos ligados à CTS, como por exemplo, os silenciamentos referentes à suposta neutralidade da Ciência e Tecnologia, anteriormente discutidos.

Em busca da superação das situações limites, destacamos elementos para práticas educativas no âmbito da educação CTS, que de alguma maneira nos ajudam a compreender e verbalizar os silenciamentos. Esses elementos, a nosso ver, estão associados à: definição dos temas, dos problemas e conhecimentos a serem abordados, e, além disso, à postura assumida pelos sujeitos.

Diante disso, enfatizamos as propostas fundamentadas na abordagem temática, descrita por Delizoicov, Angotti e Pernambuco (2011), e que têm em sua gênese, principalmente, as ideias dos educadores Paulo Freire e George Snyders. Como defendido pelos autores, nessa perspectiva, os temas constituem-se objetos de conhecimento, e assim, a estruturação curricular se dá a partir deles, rompendo com a proposta curricular tradicional, na qual o princípio estruturante é a conceituação científica. Além disso, os temas devem envolver manifestações de contradições sociais. Assim, a apreensão/apropriação de conteúdos na perspectiva da compreensão de temas coloca-se na perspectiva de instrumentalizar o estudante para a sua melhor compreensão e atuação na sociedade contemporânea. Ou seja, possibilita desafiar os estudantes não somente para compreender melhor o que é abordado, mas também atuar para transformar as situações problematizadas. Esses autores ainda destacam que a estruturação da programação segundo a abordagem de temas pode contribuir para a equipe de professores selecionar quais conhecimentos científicos precisam ser abordados no processo educacional.

Considerar currículos prontos, desvinculados da realidade dos estudantes, segundo Freire (2005), provoca o erro epistemológico. Ou seja, o querer conhecer e a curiosidade epistemológica são fundamentais no processo de ensino e aprendizagem. Dessa maneira, como critério para definição dos temas, Freire (2005) propõe o processo denominado de Investigação Temática', a partir do qual se obtém os Temas Geradores.

Para Freire (2005) é a partir das relações homem-mundo, de fatos concretos, que o tema se origina. "Investigar o 'tema gerador' é investigar, repitamos, o pensar dos homens referido à realidade, é investigar seu atuar sobre a realidade, que é sua práxis" (p. 56). Assim, segundo Freire, quanto mais tivermos uma postura ativa na investigação da temática, mais tomaremos consciência da nossa realidade e assim nos apropriaremos dela.

Tomando por base esses pressupostos, Delizoicov, Angotti e Pernambuco (2011) propõem uma dinâmica para o planejamento e organização do conteúdo programático que está estruturada em três momentos pedagógicos: problematização inicial, organização do conhecimento e aplicação do conhecimento. O primeiro momento é fundamentado na apresentação de situações reais que os estudantes conhecem, desafiando-os a falar sobre o que estão pensando, e percebam a necessidade de novos conhecimentos. A segunda etapa consiste na organização por parte do professor dos conhecimentos necessários para a compreensão dos temas e problematizações propostas inicialmente. O terceiro momento destina-se a analisar os conhecimentos construídos, visando às situações iniciais e outras que vierem a surgir. 
Para complementar as discussões, destacamos a postura a ser assumida nesses processos. A matriz teórico-filosófica freireana está comprometida com uma educação transformadora, entendida no sentido de problematização e superação das desigualdades sociais. Essa perspectiva implica uma postura dialógica (FREIRE, 2005). O diálogo não como técnica a ser usada para obtenção de resultados, mas sim como postura necessária para transformação de seres criticamente comunicativos, para reflexão e ação sobre suas realidades. É com a postura dialógica, refletindo sobre o que sabemos e não sabemos, que será possível atuar criticamente para transformar a realidade (FREIRE; SHOR, 1986). Assim, os processos educativos pautados pela articulação Freire-CTS estão preocupados, dentre outras coisas, com uma leitura crítica e intervenção da sociedade nas questões sociais relacionadas à Ciência e Tecnologia.

\section{METODOLOGIA DE ANÁLISE DOS ARTIGOS}

Neste trabalho discutimos sinalizações que podem contribuir para que práticas educativas verbalizem dimensões associadas à não neutralidade da Ciência e Tecnologia. Além das reflexões apresentadas nos itens anteriores e com a intenção de exemplificar os silenciamentos e verbalizações mencionados, realizamos uma pesquisa de cunho bibliográfico (GIL, 2008) centrada na análise de artigos científicos publicados em revistas da área de Ensino de Ciências.

As revistas, selecionadas em função da sua representatividade junto ao campo da educação CTS, foram: Alexandria - Revista de Educação em Ciência e Tecnologia; Ciência \& Educação, Ciência \& Ensino; Ensaio - Pesquisa em Educação em Ciência, Investigações em Ensino de Ciências e Revista Brasileira de Pesquisa em Educação em Ciências. Por meio do sistema de buscas dessas revistas, foram selecionados todos os artigos que fazem referência à CTS. Num segundo momento, procedeu-se à leitura do título, resumo e palavras-chave desses artigos, com a intenção de verificar se faziam referência a uma prática educativa realizada sobre o tema "questões energéticas". Nessa etapa foram encontradas cinco produções, explicitadas na tabela a seguir.

Tabela 1 - Práticas Educativas CTS que discutem o tema questões energéticas.

\begin{tabular}{|c|c|}
\hline № - Artigo & Autor - Revista/Ano \\
\hline $\begin{array}{l}01 \text { - o pro-álcool e } \\
\text { algumas relações CTS } \\
\text { concebidas por alunos } \\
\text { de 6a série do ensino } \\
\text { fundamental }\end{array}$ & $\begin{array}{c}\text { Andrade e Carvalho - } \\
\text { Ciência } \\
\text { \&Educação/2002 }\end{array}$ \\
\hline $\begin{array}{l}02 \text { - Uma experiência } \\
\text { com o } \quad \text { Projeto } \\
\text { Manhattan no ensino } \\
\text { fundamental }\end{array}$ & $\begin{array}{c}\text { Samagaia e Peduzzi - } \\
\text { Ciência } \\
\text { \&Educação/2004 }\end{array}$ \\
\hline $\begin{array}{l}03 \text { - Fontes Alternativas } \\
\text { de Energia Automotiva } \\
\text { no Ensino Médio } \\
\text { Profissionalizante: } \\
\text { análise de uma proposta }\end{array}$ & $\begin{array}{l}\text { Araújo e Formenton - } \\
\text { Alexandria/2012 }\end{array}$ \\
\hline
\end{tabular}




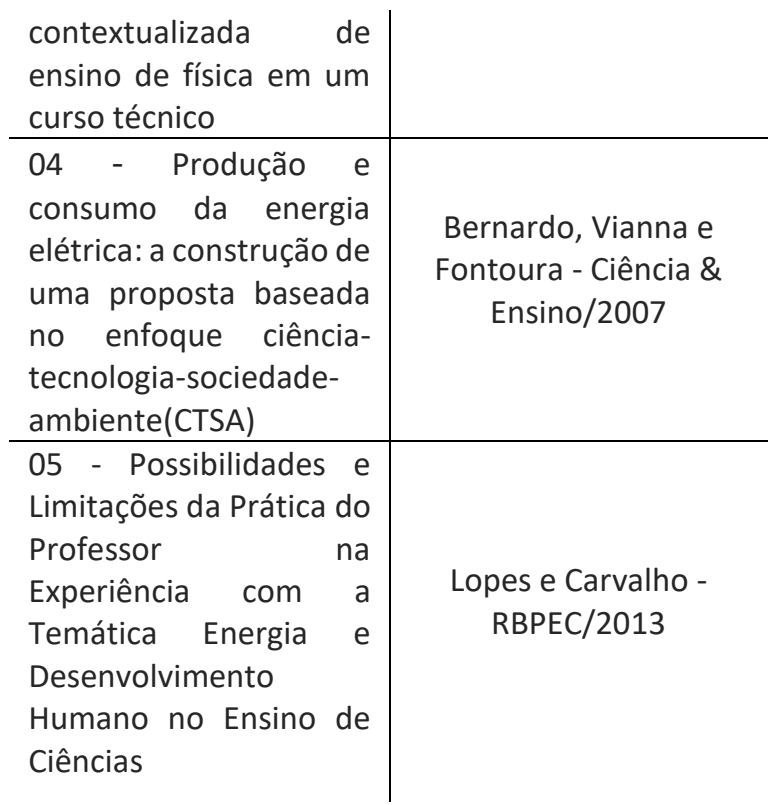

Essas cinco produções foram analisadas de acordo com a Análise Textual Discursiva (MORAES; GALIAZZI, 2016). Esse recurso teórico-metodológico não tem a pretensão de "testar hipóteses para comprová-la ou refutá-la; a intenção é a compreensão, a reconstrução de conhecimentos existentes sobre os temas investigados" (p. 33). Diante disso, o processo de análise, considerado como autoorganizado, emerge de uma sequência de três componentes: 1) unitarização: desconstrução dos textos do corpus; 2) categorização: estabelecimento de relações existentes entre os elementos unitários; e, 3) captação do novo emergente: etapa em que a compreensão é comunicada e validada. Referente às categorias de análise, destacamos que elas podem ser consideradas mistas, já que a sua construção se dá "de um conjunto de categorias definidas 'a priori', complementando-se ou reorganizando-as a partir da análise" (MORAES; GALIAZZI, 2016 , p. 25). Em específico, para a definição das categorias, utilizamos os desdobramentos teórico-práticos, realizados em Autor (2014) e Autores (2016), articulados com elementos estruturantes de propostas didáticas. Esses elementos têm como pano de fundo os pressupostos teóricos da abordagem temática freireana (DELIZOICOV; ANGOTTI; PERNAMBUCO, 2011) e referem-se à: i) Seleção e natureza dos temas; ii) Elaboração das problematizações; iii) Papel e seleção dos conhecimentos; iv) Postura: diálogo e participação.

\section{RESULTADOS}

A seguir são discutidos os resultados da análise, organizados de acordo com as quatro categorias de análise mencionadas anteriormente.

\section{i) Seleção e natureza dos temas}

Santos e Mortimer (2002), em um levantamento bibliográfico sobre currículos com enfoque CTS, destacam o posicionamento de Merryfield (1991) com relação à inserção de temas globais. Para ele, trabalhar sob essa perspectiva possibilita atingir a vida das pessoas em uma escala mundial e não apenas na compreensão e tratamento do contexto local/regional/nacional, ou seja, permite que as decisões sejam tomadas conjuntamente em contextos distintos. 
Essa perspectiva de trabalho é, em linhas gerais, predominante em propostas CTS, nas quais os temas são escolhidos levando em consideração aspectos mais globais e gerais, definidos quase que majoritariamente pelo professor, conforme evidenciado na pesquisa de Roso e Auler (2016). Para esses autores, o contexto local deveria ser tomado como ponto de partida para a elaboração das propostas. Segundo Auler (2002) o movimento CTS repercute, de forma geral, em contextos no qual as condições materiais da sociedade podem ser consideradas como razoavelmente satisfeitas e isso, possivelmente, influencia a defesa por temas em escala global. Ainda para o autor, nos países da América Latina, parcelas consideráveis da população são afetadas por falta de acesso a serviços básicos de moradia, educação, saúde, saneamento, etc. e tem um histórico colonial, com marcas que se manifestam, naquilo que Freire (2005) denominou de cultura do silêncio, ou seja, uma inexperiência de participação em processos decisórios. Assim, Auler defende que nesse contexto, é essencial problematizar a inserção de demandas/necessidades negligenciadas historicamente na produção do conhecimento científico-tecnológico.

Essa ideia também é discutida por Auler e Delizoicov (2015), que entendem que processos educacionais são essenciais e podem contribuir para a constituição de uma cultura de participação, possibilitando assim a inserção de demandas silenciadas/desconsideradas e que podem ser levantadas pelo processo de investigação temática. Essa visibilidade, oriunda dos processos educativos, poderá contribuir para inquietações e possíveis formulações de agendas de pesquisas voltadas à Ciência e Tecnologia e pautadas por problemas locais/regionais do contexto latino-americano.

Diante dessas colocações, defendemos que, mesmo que o tema seja de escala ampla e global, faz-se necessário trazê-lo para discussões que impactem de alguma maneira as contradições vividas pelos estudantes e pela sociedade. Ao mesmo tempo, isso contribui para potencializar e motivar discussões que são muitas vezes omitidas no âmbito da Ciência e Tecnologia. A proximidade com temas da realidade dos estudantes faz com que os mesmos atribuam significado para aquilo que está sendo trabalhado, abrindo caminhos para problematizar os silenciamentos expostos neste trabalho, já que se trata de situações reais e que impactam a vida dos estudantes, diferentemente, por exemplo, de propostas descontextualizadas e/ou vazias de significados que reforçam concepções associadas à suposta neutralidade.

Associado a isso, tem-se a potencialidade de temas que não necessariamente foram definidos a partir do processo de investigação temática, mas que têm a preocupação de problematizar situações concretas e contradições vividas pela sociedade. Essas propostas, por mais que estejam centradas em um tema global e geral, perpassam o âmbito local e as contradições dos sujeitos envolvidos. Destaca-se que, com isso, não estamos colocando em segundo plano a potencialidade dos processos investigativos para a definição de temas geradores; estamos, somente, ressaltando e mostrando outras possibilidades.

Diante disso, enfatizamos os artigos do corpus que evidenciaram a proximidade do tema com a realidade dos estudantes. É o caso do artigo 01, descrito por Andrade e Carvalho (2002), que trabalhou com um tema geral "Proálcool", mas focou no cenário local e situações problemáticas vivenciadas por aquela comunidade. Mesmo que o tema trabalhado esteja relacionado com o cotidiano mais amplo dos estudantes, trazer a discussão para situações locais pode 
ser considerado potencializador para atuação desses em uma análise crítica das formas, produção e apropriação do tema científico-tecnológico. Os autores afirmam que a definição do tema "Proálcool" está relacionada a diferentes fatores, entre eles,

[...] por apresentar como característica básica a polêmica em torno de questões sociais e políticas como, por exemplo, o modelo sócio-econômico utilizado para seu planejamento e execução, além de abrigar aspectos polêmicos com relação ao conhecimento científico e à aplicação da tecnologia; e por ser muito presente na vida dos alunos. (ANDRADE; CARVALHO, 2002, p. 17).

Próximo a essa perspectiva, a prática desenvolvida por Araújo e Formenton (2012), artigo 03, pautou-se de uma problemática vivenciada pelos estudantes em seu contexto profissionalizante. Ou seja, os impactos das problematizações, oriundas do tema "Fontes de Energia Automotiva", têm como pano de fundo contribuir, de alguma maneira, para atitudes críticas e reflexivas da atuação e posicionamento desses estudantes nas tomadas de decisões no contexto ao qual estão inseridos, desafiando-os, segundo os autores, na atuação profissionalizante dos mesmos.

Em síntese, entendemos que a escolha dos temas deve perpassar, de alguma maneira, por questões que tenham como pano de fundo o olhar/compreensão da realidade e das contradições sociais vivenciadas pelos estudantes. Essa perspectiva facilita a verbalização de dimensões silenciadas, apropriação, problematização, questionamento e, possível atuação sobre elas, já que tende a afetar os estudantes de alguma maneira. Logo, pode ser uma proposta com abordagem global que se articule com o local, ou ainda, de problemas locais que possibilitarão um olhar para a dimensão global.

No entanto, entendemos que o tema em si, seja discussões globais e/ou locais, não propicia linearmente um olhar crítico sobre ele, isso porque irá depender da condução e problematizações em torno da proposta. E é visando dialogar com essas perspectivas que as próximas categorias se encontram.

\section{ii) Elaboração das problematizações}

Os processos educacionais, em diferentes níveis, segundo Auler e Delizoicov (2015), possuem potencial para contribuir com a constituição de uma cultura de participação pois, colocando em pauta demandas, muitas vezes, desconsideradas, podem influenciar na formulação de políticas públicas para Ciência e Tecnologia. Para os autores, apoiados em Dagnino (2010), há a necessidade de transformar os problemas sociais vivenciados em problemas de pesquisa, e, ainda, em problemas de conhecimento. Neste sentido, Auler e Delizoicov (2015) propõem processos formativos fundamentados em uma "investigação temática reinventada" que estão "orientados para a localização e enfrentamento de demandas historicamente negligenciadas, com produção de conhecimento novo" (p. 292). Para isso, é necessário um coletivo multidisciplinar, formado pela comunidade e/ou por pesquisadores, envolvidos politicamente com transformações sociais.

É nesse sentido que a presente categoria, articulada à anterior, se encontra, pois possibilita olhar para os problemas com um viés investigador e de verbalização 
de questões silenciadas. Assim, quais problemas/problematizações são passíveis desse viés?

Ao problematizar uma situação, em propostas educacionais CTS, em linhas gerais, tem-se como ponto de partida questões motivadoras, associadas a uma "situação-problema contextualizada" e articuladas ao tema trabalhado. No tema em discussão - questões energéticas -, poderíamos, por exemplo, questionar: "Quais são as fontes de energia utilizadas na geração de eletricidade?"; "De que maneira acontecem as transformações de energia até chegar às nossas residências?", ou ainda, "Como se dá a geração de eletricidade nos geradores eólicos?".

Essas problematizações contribuem de maneira significativa para uma análise teórico-conceitual do problema. No entanto, concordamos com Auler, N. e Auler, D. (2015) quando destacam o processo de problematização inicial articulado com uma função além da simples motivação para inserir conhecimentos científicos novos. Além disso, esse momento deve proporcionar "uma ligação desses conhecimentos com situações reais que os estudantes conhecem e presenciam, representando desafios a serem enfrentados" (p. 21). Assim, questionamos: até que ponto as questões colocadas anteriormente problematizam contradições vividas, demandas desconsideradas, desafios a serem enfrentados ou, olhares críticos sobreas interações ciência-tecnologia-sociedade e de questões silenciadas sobre a não neutralidade da Ciência e Tecnologia?

Ou seja, as problematizações precisam ir além de uma análise teórica do problema e contribuir para verbalizações de dimensões silenciadas e/ou pouco críticas. Essa categoria, portanto, busca verbalizar problemas que envolvem influências da sociedade sobre a Ciência e Tecnologia e vice-versa, a importância da educação científica, a natureza e implicações valorativas da produção e desenvolvimento científico-tecnológico, pontos controversos, modelos de sociedade, participação social na concepção e execução de Ciência e Tecnologia, aspectos, muitas vezes, silenciados em práticas educativas CTS. Esse momento de problematização torna-se importante, também, por fundamentar o andamento da prática educativa, isso porque, a partir do diálogo proposto inicialmente, será possível identificar visões distorcidas, limitadas e potencializadoras de debates e reflexões.

Quando falamos da questão energética, em especial a energia elétrica, não há dúvidas de que se trata de um problema global, mas com impactos locais e viceversa. Mas, o que seria problematizar esse tema levando em consideração as verbalizações dos silenciamentos em uma escala local? E ainda, na perspectiva de superação de contradições sociais?

Para além de discussões voltadas à economia de energia, como, por exemplo, as relacionadas à compra de equipamentos mais eficientes, ou hábitos de consumo consciente, torna-se necessário refletir sobre a matriz elétrica, possíveis alternativas para aspectos relacionados a uma política nacional de energia elétrica, potencialidades para fontes de energias alternativas, tarifas, privatizações e interrupções/blecautes. Ou seja, faz-se necessário ampliar as problematizações que influenciam apenas um olhar para a participação em uma escala micro e marcada pelo "pós-produção", como hábitos conscientes de uso de energia elétrica ou apenas decidir sobre o uso do álcool ou da gasolina em função da relação custo-benefício. 
O espectro de problematizações deve ser pensado também para questões que tenham como pano de fundo alertas, alternativas e concepções que superem a suposta neutralidade da Ciência e Tecnologia, como interesses de grupos dominantes em estabelecer tipos e formas de fornecimentos; decisões, muitas vezes, não restritas ao conhecimento técnico, mas também político. Ou, por que há pouco incentivo às políticas de produção e desenvolvimento científicotecnológico referente à possibilidade de usos de fontes alternativas de energia? Sendo o Brasil um país com diversidades naturais e culturais, quais políticas públicas referentes à questão energética são pensadas diante dessas diversidades? As comunidades locais participam desse processo? Quais as potencialidades e limitações, devido ao recurso hídrico brasileiro e aspectos econômico-financeiro e socioambiental, das pequenas centrais hidrelétricas? Problematizações como essas possibilitarão um olhar crítico para um problema amplo e global, investigando, por exemplo, o que seria mais interessante para o contexto local brasileiro considerando as desigualdades sociais, as necessidades da população, e, os diferentes recursos naturais existentes no nosso país.

Corroborando com essas sinalizações e olhando para o nosso corpus de análise, Araújo e Formenton (2012) ampliam o olhar para possíveis problematizações que perpassam questões valorativas da área científicotecnológica. Isso evidencia discussões que verbalizam silenciamentos identificados nas perspectivas "i" e "iv", ou, seja, indicam que a questão valorativa da Ciência e Tecnologia está presente em todo o processo e que decisões técnicas acompanham decisões políticas. Segundo os autores,

\footnotetext{
[...] entre as discussões geradas pelas possíveis mudanças tecnológicas de uma fonte de energia automotiva para outra, esbarramos em obstáculos não apenas técnicos quando, por exemplo, não conseguimos captar energia solar em quantidade suficiente para suprir as necessidades das pessoas, mas também de interesses de grupos específicos e estatais que dominam o fornecimento e distribuição de petróleo e seus derivados no Brasil e no mundo. (ARAÚJO; FORMENTON, 2012, p. 12).
}

Ainda na potencialidade de verbalização da perspectiva "i", os autores relatam que a ação didática procurou motivar os estudantes "a refletirem e compreenderem melhor alguns aspectos envolvidos nas políticas de incentivo ao desenvolvimento da C\&T e a possibilidade do uso de uma fonte alternativa de energia, no caso preferencialmente a eletricidade" (ARAÚJO; FORMENTON, 2012, p. 13).

O artigo 01, desenvolvido por Andrade e Carvalho (2002), também traz algo relevante quanto à possibilidade das problematizações a serem levantadas em propostas CTS. Segundo o planejamento dos autores, houve uma atividade relacionada com "as alterações sociais, políticas, econômicas e ambientais ocorridas com a implantação do Pro-álcool; papel da participação social nas políticas de desenvolvimento científico e tecnológico" (p. 07), algo, muitas vezes, não comum em problematizações no Ensino de Ciências e até mesmo na educação CTS e, proporcionaram, por exemplo, verbalizar as perspectivas "i" e "vi" (ampliação dos atores envolvidos no processo de decisão em temas relacionados a área de Ciência e Tecnologia como superação das decisões tecnocráticas ditas como neutras).

Além dessas exemplificações, a prática desenvolvida por Lopes e Carvalho (2013) também evidencia alguns aspectos que contribuem para a nossa análise, 
pois, de alguma maneira, verbalizaram as perspectivas "i" e "ii" (a participação pósprodução apesar de importantes é limitante, isso porque ficar restrito apenas a esse mecanismo pode levar a ideia de que a sociedade tem enquanto objetivo tirar o melhor proveito do produto científico-tecnológico). Segundo os autores, as discussões relacionadas ao tema questões energéticas na Escola devem iniciar com a

problematização do atual modelo de desenvolvimento, que é assegurado na produção e no consumo de energia e que orienta as organizações sociais. Por isso, é necessário o reconhecimento destas relações e a crítica quanto à produção e ao consumo de bens e serviços. Estas relações que têm levado a humanidade para as atuais preocupações com o ambiente e com a escassez energética. (p. 06).

Também destacam outras questões possíveis de serem trabalhadas no âmbito educacional, como:

\footnotetext{
a) o questionamento das ações e aplicações da ciência e da tecnologia; b) a compreensão e o questionamento da própria construção do conhecimento científico (abordagens epistemológicas); c) os debates sobre a pretensa neutralidade da ciência; d) as relações dinâmicas do desenvolvimento das C\&T; e) a compreensão dos conceitos relacionados à energia e; f) a compreensão das relações CTSA complexas que envolvem a produção e o consumo de energia. (p.07).
}

Diante do exposto, ressaltamos a importância de questões problematizadoras que articulem as esferas global e local, pois potencializam a verbalização de dimensões muitas vezes esquecidas, e podem alavancar discussões e reflexões que vão além dos conteúdos específicos curriculares, para possíveis inserções em pontos de pauta, por exemplo, nas agendas de pesquisa científico-tecnológica.

No entanto, levando em consideração as sinalizações almejadas nesse trabalho, de que maneira a construção do conhecimento deve ser delineada? Qual é o papel e quais conhecimentos perpassam uma análise crítica das problemáticas evidenciadas nessa categoria? É a partir dessas discussões e inquietações que a análise a seguir emerge.

\section{iii) Papel e seleção dos conhecimentos}

Para a compreensão e problematização do papel e definição dos conhecimentos necessários para o desenvolvimento de práticas educativas pautadas pela abordagem de temas sociais da área de Ciência e Tecnologia, que tenham como pano de fundo verbalizar silenciamentos da suposta neutralidade, apresentamos os estudos desenvolvidos por Samagaia (2016) e Michel Callon (1998) referentes aos modelos de comunicação científica existente na relação entre ciência e sociedade. A utilização desses estudos se dá pela importância dada ao papel e tipos de conhecimentos empregados em processos democráticos em Ciência e Tecnologia, aspecto essencial na educação CTS. Tomando por base esses trabalhos destacamos os três modelos: da instrução pública, do diálogo e, da coprodução dos saberes.

O modelo da instrução pública, fundamentado na lógica da comunicação linear entre especialistas e demais atores sociais, pode ser caracterizado na 
educação CTS pelo modelo de decisões tecnocráticas, o qual se privilegia apenas o conhecimento científico. Nessa lógica, o conhecimento é visto como universal, objetivo, de verdades inquestionáveis e produzido unicamente pelos cientistas.

Trazendo essas discussões para as práticas educativas destaca-se o trabalho de sala de aula fundamentado apenas pelo conhecimento científico. Diante disso, caso os processos de ensino-aprendizagem e discursos em sala de aula sejam marcados apenas por esse conhecimento os mesmos inviabilizam/limitam o trabalho com problemas/temas reais, complexos por natureza e com implicações socioambientais, visto que apenas um único tipo de conhecimento não dá conta da complexidade dos temas e problematizações trabalhados, e sim fragmenta e simplifica, distanciando-se das realidades vivenciadas. Além disso, práticas educativas construídas sobre esse viés contribuem para alimentar discursos da suposta neutralidade científico-tecnológica, respaldando decisões tecnocráticas. Assim, o papel dado ao conhecimento científico, nessa lógica, é de recebimento linear entre os atores envolvidos, logo daqueles que possuem o conhecimento para aqueles que recebem sem questionamento, portanto do professor para o estudante. Há também a funcionalidade útil desse conhecimento visando uma boa aplicação na vida cotidiana. Questiona-se nesta ideia a perspectiva de contribuir apenas para uma cultura de "participação pós-produção", o que é importante, mas limitante, visto que não questiona e possibilita constituir modelos distintos de sociedade, esses marcados por outros desenvolvimentos de Ciência e Tecnologia e que perpassam por conhecimentos e questões valorativas não reduzidos apenas ao científico. Ou seja, há a necessidade de questionar o conhecimento e questões valorativas e não apenas usá-lo, aspectos marcantes da não neutralidade científico-tecnológica.

Complementando essas discussões e visando a problematização dos conhecimentos necessários para o enfrentamento dos problemas propostos, bem como o desenvolvimento de uma cultura científica que potencialize uma participação ampliada em decisões relacionadas à Ciência e Tecnologia, Santos, M. A. (2009) defende a necessidade de associarmos, cada vez menos, a imagem escolar da ciência daquela que corresponde a uma disciplina neutra, objetiva e desvinculada das questões sociais, filosóficas, políticas, econômicas e éticas. E ainda, na relação de constituição dos estudantes para lidar com as situações do dia a dia, na sociedade científico-tecnológica, faz-se necessário sensibilizá-los "para a riqueza da diversidade, da interdisciplinaridade, da "manipulação de símbolos", do diálogo entre saberes e para os efeitos profundos dos espantosos desenvolvimentos tecnocientíficos" (p. 21). Entendemos que a busca pela formação de cidadania, e outros objetivos CTS, os conhecimentos científicos vistos como uma construção humana e de um coletivo, somados a estratégias, atitudes, valores relacionados com contextos de produção e execução de Ciência e Tecnologia, contribuem, conforme a autora, em evitar que o conhecimento científico separe, cada vez mais, os especialistas e cientistas dos outros atores sociais.

Essa perspectiva converge com a próxima discussão sobre conhecimento e que está articulada ao segundo modelo discutido em Callon (1998) e Samagaia (2016), denominado de modelo do diálogo. Esse é caracterizado por um processo democrático pautado por interações dialógicas entre diferentes atores sociais. $O$ conhecimento científico no interior dessas relações é fundamental, no entanto é visto como insuficiente na identificação e solução dos problemas vividos, ou seja, 
é visto como adequado aos temas sociais vivenciados caso seja considerado juntamente com a integração e ampliação de variáveis envolvidas e não apenas àquelas científicas. Portanto, há consideração de conhecimentos diversos.

Corroborando com essas discussões têm-se as reflexões do cientista social Boaventura Sousa Santos (2007), quando propõe problematizar a monocultura ${ }^{2}$ do saber e do rigor. Essa monocultura está fundamentada na problematização de que o único saber rigoroso é o científico, ou seja, outros tipos de conhecimentos não têm validade, muito menos o rigor do conhecimento científico. A proposição feita pelo autor está no fato dessa concepção deixar de fora muitas realidades da sociedade, já que há práticas sociais que estão fundamentadas em outros conhecimentos. Sousa Santos (2007) para exemplificar essa monocultura utiliza a ideia de que ela (como a soja) exclui outros conhecimentos, produzindo segundo ele "epistemicídio", ou seja, a morte de conhecimentos alternativos. Não somente os conhecimentos alternativos são desconsiderados, como também as comunidades e povos cujas práticas estão fundamentadas nesse tipo de conhecimento. Como alternativa a essa visão hegemônica, o autor propõe a ecologia dos saberes, possibilitando que a ciência não seja apenas vista como monocultura, mas sim, como "uma ecologia mais ampla de saberes, em que o saber científico possa dialogar com o saber laico, com o saber popular, com o saber dos indígenas, com o saber das populações urbanas, com o saber camponês" ( $p$. 32-33). A ecologia dos saberes entende que todas as práticas entre os seres humanos, e destes com a natureza, implicam em mais de uma forma de saber. Ou seja, essa discussão, apesar de estar num contexto social mais amplo, contribui de maneira significativa para essa categoria, pois amplia a nossa discussão referente aos conhecimentos existentes e a necessidade de dialogá-los, seja no âmbito social, seja na academia ou na escola, problematizando a ideia de ciência como saber hegemônico e suficiente para resolver os problemas, inclusive os sociais.

Essas discussões se aproximam, em partes, com as práticas educativas voltadas pela abordagem de temas reais defendidos pela articulação Freire-CTS, visto que há uma defesa por posturas dialógicas e valorização de diferentes conhecimentos pautados por leituras de mundo. Porém, o destaque do modelo dialógico (CALLON, 1998), articulado às discussões das práticas educativas, está no fato de que apesar de serem considerados diferentes conhecimentos e posturas dialógicas, os especialistas, no caso os professores e/ou outros atores especializados, são os únicos capazes de produzirem de fato o conhecimento científico assim, o papel dado ao conhecimento é da potencialidade dialógica entre diferentes atores sociais. O conteúdo do diálogo na prática educativa, portanto os diferentes conhecimentos e leituras de mundo, está orientado, de maneira geral, às discussões que envolvem levantamentos, problematizações e dúvidas sobre os temas trabalhados, logo, como motivação do processo e não um engajamento integral no processo educacional, de construção do conhecimento e desenvolvimento de habilidades para questioná-lo e usá-lo em possíveis decisões sobre temas sociais de Ciência e Tecnologia, como por exemplo, o desenvolvimento de argumentação e conta-argumentação. Ou seja, os estudantes possuem "vozes ativas", inclusive nas problematizações mais críticas pautadas categoria anterior, porém na etapa de construção do conhecimento científico ainda são os professores/especialistas/gestores os únicos atores capazes de produzirem conhecimento. 
Para complementar e problematizar as limitações apresentadas sobre o papel do conhecimento nas discussões acima, propomos o terceiro modelo apresentado por Callon (1998) que é denominado de coprodução dos saberes. Nesse processo democrático, que considera a interação de diferentes atores atuando sobre demandas vivenciadas diretamente por eles, o conhecimento científico também é visto como essencial, porém diferencia-se por considerar a possibilidade de produção conjunta de conhecimento entre atores sociais heterogêneos. Assim, os conhecimentos que vão dos mais universal (científicos) aos mais específicos (vivenciados por atores sociais diante de problemas/temas que os atingem) são discutidos, construídos e apropriados por um coletivo, que inclui especialistas e diferentes atores sociais. Dessa forma, neste modelo, o papel dado ao conhecimento é ampliado quando comparado aos anteriores, isso porque há uma aprendizagem coletiva sobre os diferentes conhecimentos. Ou seja, os conhecimentos se cruzam e geram o próprio processo de coprodução (CALLON, 1998).

Esse entendimento sobre os conhecimentos e a possibilidade de construção conjunta pode ser relacionada àquelas práticas educativas Freire-CTS que estão fundamentadas por um exercício curricular que envolve a discussão de diferentes valores e não apenas os científicos e que problematizam formas alternativas de organização social. Práticas educativas essas que têm como pano de fundo contradições sociais, portanto, se aproximam dos pressupostos do PLACTS. Junto a isso, possibilitam nesse processo conjunto e colaborativo desenvolver habilidades de construção de conhecimento, como por exemplo mobilizar; argumentar; contra-argumentar; e, desenvolver a capacidade de reflexão e organização de discursos frente às situações trabalhadas. Habilidades essas que possibilitam olhar para os temas reais com maior criticidade, posicionamento e engajamento frente a eles. Ou seja, o processo de coprodução, além de considerar conhecimentos e valores diversos e diferentes "vozes ativas", promovem a construção de conhecimento coletivamente tendo como objetivo central o engajamento e enfrentamento de situações problemáticas.

Retomando o tema "questões energéticas", diante das problematizações explicitadas na categoria anterior, é perceptível que se considerarmos apenas o conhecimento técnico-científico, respaldado pelo modelo de instrução pública, daremos um olhar reducionista para elas. Ampliar os saberes e discursos de outras áreas como ambientalistas, economistas, movimentos sociais, povos tradicionais, entre outros, que propiciem "outros olhares" e questões valorativas, possibilitará compreender o problema/tema sobre diferentes vertentes e argumentos, dando um viés mais humanístico e, valorizando regionalidades e comunidades locais. Esses olhares, no âmbito educacional, por exemplo, tornam-se mais viáveis caso o tema perpassar, conforme já discutido, as escalas global e local, identificando assim diferentes conhecimentos e sujeitos que o produzem. A questão energética, assim como outros temas muito comuns na mídia, coloca para a Escola um papel muito importante, pois, ao construir os conhecimentos com os estudantes, eles, ao mesmo tempo, precisarão apoiar seus argumentos fundamentados no arcabouço da ciência, mas também, dialogar com outros saberes e valores. Isso é indispensável quando o discurso está na formação de cidadãos mais críticos, reflexivos, conscientes e atuantes na busca por uma sociedade mais justa e igualitária, logo, destaca-se a importância do modelo dialógico e de coprodução de conhecimentos nas práticas educativas. 
Tanto o conhecimento científico como outros saberes foram revelados fundamentais no processo de construção do conhecimento em alguns artigos analisados. Segundo Araújo e Formenton (2012), para que os estudantes tenham uma compreensão de vida em sociedade com responsabilidade, faz-se necessário um embasamento científico das suas opiniões. Algo que se torna viável no contexto da educação científica. No entanto, quando se trabalha com um problema/tema com implicações sociais, segundo os mesmos autores, sua compreensão torna-se possível a partir das inter-relações CTS.

Ouvir, compreender e identificar outros saberes e sujeitos da sociedade, revelando, por exemplo, a verbalização da perspectiva "iv" (conhecimento científico como necessário, mas insuficiente para resolução de problemas sociais), foi destacado pelo artigo 01, descrito por Andrade e Carvalho (2002), no registro da proposta, "Identificação pelos alunos das ideias e dos conhecimentos das pessoas da comunidade acerca do processo de produção de álcool [...] (p. 07)". Essa perspectiva pode ajudar a compreender o problema sob diferentes pontos de vista, contribuindo assim para a análise ampla da situação, bem como do posicionamento da mesma, avançando para proposições dialógicas.

Lopes e Carvalho (2013), artigo 05, apresentam discussões fundamentais referentes à verbalização das perspectivas "iv" e " $v$ " (decisões técnicas acompanham decisões políticas). Segundo os autores, a temática "questões energéticas", por tratar de discussões referentes às formas de obtenção, distribuição e consumo de energia, aborda desde questões conceituais até processuais e axiológicas. Assim, para eles "é necessária a contraposição de conceitos, como desenvolvimento, sustentabilidade, produção e consumo de energia elétrica, bem como conceitos de ética e de risco" (p. 215). E ainda, em uma perspectiva de discussão democrática sobre esse tema em sala de aula, os autores entendem que é inviável caso o papel dos professores se restrinja ao campo do conhecimento científico. Logo, para eles, deve acontecer sistematicamente a apresentação de pontos de vistas diferentes, o julgamento de argumentos fundamentados em ideologias, como de cientistas, governo e grupos minoritários.

A discussão e entendimento do tema proposto e outros temas complexos por natureza, será satisfatória quando o conhecimento científico somado a outros saberes contribuir para explicar, cada um dentro do seu contexto, os fenômenos, os conceitos, as teorias, a natureza do conhecimento, reflexões e argumentação sobre implicações e alternativas diante de impactos socioambientais, produção e execução da Ciência e Tecnologia, por exemplo. Assim, quando os objetivos são os propostos na Educação Freire-CTS e PLACTS, é perceptível que os conhecimentos necessários perpassem desde o campo científico ao político, econômico, social, ambiental, popular, entre outros, não hierarquizando o conhecimento científico e seus especialistas sobre os demais conhecimentos e atores sociais. O viés está em questionar cada forma de produção, apresentando potencialidades e limitações dentro do seu contexto. Entendemos que o processo de democratização de temas sociais relacionados à área científico-tecnológica tem como algo fundamental o reconhecimento de diferentes conhecimentos, valores e sujeitos, algo que pode ser iniciado no âmbito das práticas educativas, e é o foco de discussão da próxima categoria.

\section{iv) Postura: dialogicidade e participação}


Essa categoria surge da busca de uma análise mais crítica dos discursos, muito comuns e ainda frágeis, em propostas educativas CTS, de democratizar a tomada de decisão, ampliar a participação e o controle social em temas relacionados à Ciência e Tecnologia. Os estudos CTS têm em sua gênese uma natureza política e social, sendo um dos seus principais objetivos a constituição de participação da sociedade nos rumos da atividade científico-tecnológica. No contexto educacional, segundo García, Cerezo e López (1996), CTS repercutiu na busca por um Ensino de Ciências mais crítico e contextualizado, o qual possibilitaria promover a participação social nas questões relacionadas à Ciência e Tecnologia.

Essa participação tem assumido, no contexto educacional, diferentes perspectivas, como sinalizado por Strieder (2012). Na análise realizada pela autora, foram apontados cinco níveis de participação. $O$ primeiro e menos crítico está na perspectiva da informação e reconhecimento da Ciência e Tecnologia na sociedade. O segundo nível ocorre, segundo a autora, no contexto micro, no qual as decisões são tomadas individualmente e estão geralmente associadas aos produtos científico-tecnológicos. O terceiro, em uma escala macro, são as decisões ditas coletivas, que contemplam as discussões dos problemas e impactos da Ciência e Tecnologia. A participação, no quarto nível, acontece diante do "reconhecimento das contradições e por mecanismos de pressão, principalmente, no processo de produção" (p. 202). E, por fim, no nível mais crítico, está a participação nas esferas políticas, contemplando a compreensão e discussão de políticas públicas.

Além disso, constata-se uma fragilidade, no contexto brasileiro, referente ao incentivo/engajamento à participação social em questões voltadas ao desenvolvimento científico-tecnológico. Os encaminhamentos em torno da participação social, em linhas gerais, fundamentados pelo movimento CTS estão preocupados com a avaliação dos impactos gerados pelo desenvolvimento científico-tecnológico, ou seja, em avaliar aspectos positivos e negativos do uso dado a Ciência e Tecnologia. Em publicações da área, conforme identificados em Autor (2014), são frequentes as afirmações que evidenciam a importância da participação e os questionamentos da sociedade perante as consequências do produto científico-tecnológico, viés importante, porém limitante, conforme já mencionado. Considerando o PLACTS defendemos a necessidade de uma participação que vai além da avaliação pós-produção de Ciência e Tecnologia, suscitando uma reflexão sobre o direcionamento dado à atividade científicotecnológica, sobre a agenda de pesquisa. Ou seja, faz-se necessário também avaliar impactos da sociedade, ou setores desta, no direcionamento dado ao desenvolvimento científico-tecnológico.

Nesse contexto, merecem destaque as ideias de Paulo Freire. Na sua perspectiva, para que haja a libertação dos seres humanos, não se pode começar por aliená-los ou simplesmente mantê-los alienados. Libertar-se não é algo que se deposita nos seres humanos, nem "[...] uma palavra a mais, oca, mitificante. É a práxis que implica a ação e reflexão dos homens sobre o mundo para transformáIo" (FREIRE, 2005, p. 93). Assim, conforme já exposto, para que a sociedade participe da construção da sua própria história, segundo Freire (2005), é essencial a superação da cultura do silêncio, da alienação, da passividade, em busca de uma educação problematizadora e crítica. Na perspectiva educacional de Freire (2005), alfabetizar é muito mais do que apenas ler palavras, e sim, deve propiciar a leitura do mundo. Pois, é através da alfabetização e da educação que os sujeitos, através 
da leitura do mundo e da palavra, terão condições de transformar a sua consciência ingênua em crítica e atuar na sociedade.

Diante dessas colocações, faz-se necessário ampliar o olhar para as práticas educativas. Não há dúvidas de que é necessário inserir mecanismos de participação, em diferentes níveis, no contexto educacional. Mas, como proceder? Qual o papel da Escola diante da inserção desses diferentes níveis? E ainda, quais os potenciais e limitações das práticas educativas CTS e do contexto escolar para tornar isso viável?

Nesse sentido, pensando nas práticas educativas, o diálogo oriundo das problematizações da segunda categoria - elaboração das problematizações -, por exemplo, possibilita dar voz às diferentes perspectivas e valores do problema trabalhado. Além de proporcionar a superação da cultura do silêncio, com o diálogo e voz ativa dos estudantes em sala de aula, a forma de problematizar as questões e os conhecimentos necessários para compreendê-las e argumentá-las, no nosso entendimento, influenciam diretamente nos diferentes níveis de participação.

Problematizar questões que tenham como fundamento apenas o diálogo conceitual, na perspectiva de aproximar os conceitos ao contexto dos alunos, possibilita, no nosso entender, desenvolver o nível menos crítico de participação, proporcionando apenas o reconhecimento da Ciência e Tecnologia na sociedade. Assim como construir o conhecimento sob o viés apenas técnico-científico, também ficaria restrito a esse nível. Destaca-se que pode haver práticas educativas com essa abordagem que ampliem o olhar, não ficando apenas nesse nível de participação. No entanto, acreditamos que problematizações conceituais, mesmo perpassando por discussões contextualizadas, apesar de importantes, dificultam a construção de mecanismos ampliados de participação para níveis mais críticos.

Ressaltamos novamente que o papel da Escola está, entre outras coisas, na formação de cidadãos atuantes na sociedade, o que não leva diretamente a uma mudança imediata nas políticas públicas. Cabe à Escola e às ações educativas, as quais, entendemos ter papeis fundamentais, proporcionarem esses olhares e diálogos que poderão despertar práticas participativas, bem como a defesa delas. Porém, conforme discutido, poderão ser incorporados em diferentes níveis, a depender dos encaminhamentos realizados, e, na amplitude alcançada diante do viés defendido nas categorias anteriores.

As práticas educativas analisadas propiciaram, de uma maneira pontual, possíveis mecanismos de participação em diferentes níveis, sinalizando, nesse sentido, dimensões referentes à perspectiva "vi" (ampliação dos atores envolvidos no processo de decisão em temas relacionados à área científico-tecnológica como superação das decisões tecnocráticas ditas como neutra). Defende-se aqui, que para que haja uma efetiva participação/democratização em temas científicotecnológicos faz-se necessário haver diálogos entre diferentes atores sociais. Podese identificar nos artigos 02 (ANDRADE; CARVALHO, 2002), 03 (ARAÚJO; FORMENTON, 2012) e 05 (LOPES; CARVALHO, 2013) atividades relacionadas à socialização dos estudos e, a partir disso, simulações em diferentes níveis de participação do tema proposto.

No artigo 03, por exemplo, foi realizada uma atividade de debate, que proporcionou "confrontos" sob pontos de vista divergentes, que segundo os autores, viabilizou um diálogo sobre questões não apenas técnico-científicas, mas 
também sobre "[...] conexões com consumo, produção de alimentos, emprego, saúde pública, derretimento de geleiras, desmatamento de florestas, aquecimento global, contaminações e outras questões sócio-ambientais relevantes" (p. 11).

No artigo 02, essa atividade também foi identificada. Nessa, cada "grupo de cientistas" representado pelos estudantes, teve uma aula disponível para argumentação dos seus posicionamentos, e depois isso, um debate entre os grupos. A finalização dessa dinâmica deu-se com a decisão, do grupo que representava a sociedade em geral, a respeito dos rumos que seriam tomados sob o problema em questão, ou seja, deu-se voz aos estudantes, os quais representavam atores sociais, questionando de alguma maneira, decisões apenas tecnocráticas.

Incorporando essas análises, tem-se a prática do artigo 05 , na qual segundo os autores, os estudantes foram conduzidos à participação democrática nas questões trabalhadas. Os autores, apoiados em Cross e Price (2002), destacam que nesse modelo de atividade é possível desenvolver diferentes atitudes como: a compreensão das justificativas dos seus posicionamentos, o reconhecimento da importância do conhecimento científico para debates democráticos e, também, a insuficiência desses em certas circunstâncias; e, o papel das "pesquisas de campo e da literatura" (p.216), que propiciam um contato maior com outras fontes de informação, não restrita apenas ao olhar do professor. Para os autores, práticas pautadas em perspectivas como estas possibilitam um ambiente propício para discussões e formação de posicionamento crítico dos estudantes.

\section{SINALIZAÇÕES PARA A EDUCAÇÃO EM CIÊNCIAS}

O presente trabalho se encontra em um campo com diferentes abordagens e perspectivas educacionais: o da Educação CTS. Mas, mesmo nesse contexto, entendemos que existem objetivos e pressupostos oriundos da gênese do movimento CTS e sua repercussão na educação, que necessitam ser identificados e implementados nas práticas educativas. Com esse intuito, buscamos promover um exercício articulador de verbalizar dimensões silenciadas sobre a suposta neutralidade da Ciência e Tecnologia em práticas educativas CTS. Destaca-se que a suposta neutralidade, segundo alguns autores, está relacionada com a origem do movimento CTS; assim, problematizá-la contribui para uma compreensão mais críticas das interações CTS, bem como, para a constituição de uma sociedade mais participativa em temas relacionadas à Ciência e Tecnologia.

Enquanto exercício articulador dessas perspectivas, propomos elementos possíveis para a construção de práticas educativas CTS. Destacamos que esses elementos, discutidos em quatro categorias - i) Seleção e natureza dos temas; ii) Elaboração das problematizações; iii) Papel e seleção dos conhecimentos; iv) Postura: diálogo e participação - nascem dos referenciais adotados neste trabalho e são aprofundados e exemplificados a partir dos trabalhos analisados, centrados em práticas educativas que abarcam discussões sobre a questão energética.

Dessa análise constatamos que, mesmo que pontualmente, há indicativos de práticas que de alguma maneira verbalizam dimensões silenciadas e propiciam atividades e ações participativas em sala de aula. No que diz respeito à seleção e natureza dos temas, dois artigos explicitam preocupações com a compreensão da realidade e a superação de contradições sociais, potencializando a análise crítica 
das formas, produção e apropriação do tema científico-tecnológico em questão. Também, em três artigos encontramos problematizações relacionadas às políticas de produção e desenvolvimento científico-tecnológico, verbalizando que há valores incorporados na origem/concepção e execução da Ciência e Tecnologia. Quanto aos conhecimentos necessários para a compreensão dos temas e à postura dialógica, dois artigos destacaram a necessidade de considerar outros saberes e três a realização de atividades centradas em debates e confronto de opiniões, contribuindo para superar a tecnocracia e desenvolver uma cultura de participação.

Destaca-se ainda, que não ficou perceptível o processo de construção de conhecimento fundamentado pela coprodução conjunta, perspectiva que merece maior atenção e aprofundamento em pesquisas futuras. Mesmo que algumas práticas tenham mostrado elementos importantes para a discussão da não neutralidade, verificam-se ainda algumas dimensões a serem questionadas, como por exemplo, a hierarquia dada à voz técnica (grupos de cientistas) e ao conhecimento científico. Entende-se a importância desse conhecimento, no entanto, em um processo educativo faz-se necessário problematizar a hierarquia desse saber, e os valores que acompanham suas decisões, possibilitando assim alcançar níveis mais críticos de participação.

Nesse sentido, sinalizamos a importância de desenvolver práticas educativas centradas em problemas reais relacionados à questão energética e que tragam à tona as limitações do conhecimento científico para as decisões a serem tomadas e as contradições envolvidas nesse processo. Isso pode ser explicitado de diferentes formas, por exemplo, ao discutir decisões distintas e suas relações com os interesses dos atores sociais envolvidos nos processos decisórios. Também, destacar a complexidade e dinamicidade das variáveis (econômicas, políticas, culturais, etc.) intrínsecas às questões, pode favorecer posicionamentos mais críticos diante delas. 


\title{
CTS education and the non-neutrality of science-technology: a look at educational practices focused on the energy issue
}

\begin{abstract}
This paper seeks to verbalize silenced dimensions and associated with supposed neutrality in order to contribute to the elaboration of educational practices. Composed of a bibliographical research, the corpus of analysis was formed by articles, self-identified by educational practices STS focused on the energy issue. To obtain the results, we used the Discursive Textual Analysis, which resulted in the following mixed categories, resulting from a theoretical-practical development of STS educational practices and elements of Freire's thematic approach: selection and nature of themes; elaboration of problematizations; role and selection of knowledge; and, dialogical and participative posture. Among the results, we highlight practices indicative of silenced dimensions and provide participatory activities and actions in the classroom. In addition, we emphasize the importance of addressing real problems and social contradictions, which make it possible to problematize knowledge and voices beyond technical-scientific, contributing to overcoming naive visions and building democratic processes.
\end{abstract}

KEYWORDS: STS education. Non neutrality of science technology. Educational practices. 


\section{NOTAS}

1 Considerando que há diversas maneiras de se referir às relações CTS no contexto do Ensino de Ciências, como "Enfoque CTS", "Perspectiva CTS", "Abordagem CTS", entre outros, optamos por "Educação CTS" por entender que, apesar de ser um campo polissêmico, ao utilizarmos esse termo estamos considerando discussões articulado a um contexto amplo, que vai desde uma situação de questionamento, intervenção, direcionamento e reivindicações sobre temas sociais de Ciência e Tecnologia que estejam associadas na busca por mecanismos ampliados de participação, inclusive nas políticas públicas, até o contexto educacional voltado para proposições curriculares e práticas educativas, alinhados aos propósitos da área e que contribuam para alcançar os mecanismos citados.

2 Destaca-se que a concepção linear/tradicional da relação entre Ciência e Tecnologia está articulada ao modelo linear de progresso, no qual o desenvolvimento científico gera desenvolvimento tecnológico, este por sua vez gera o desenvolvimento econômico, que por fim irá gerar um desenvolvimento social, sendo que, nessa perspectiva somente decisões tecnocráticas são aceitáveis (GARCIA; CEREZO; LÓPEZ, 1996).

3 Segundo Delizoicov, Angotti e Pernambuco (2002) apoiados em Freire (2005) essa dinâmica abrange um processo de cinco etapas: 1) levantamento preliminar - reconhecer o ambiente em que vive o educando e sua situação sócioeconômica-cultural; 2) escolha de situações que sintetizam as contradições vividas, bem como a escolha de codificações; 3 ) realização de diálogos descodificadores, obtendo destes os temas geradores; 4) redução temática - consiste em um trabalho de equipe interdisciplinar, com o objetivo de elaborar o programa e identificar quais conhecimentos são necessários para a compreensão dos temas; e, 5) desenvolvimento do programa em sala de aula.

4 Sousa Santos (2010) em uma discussão contra-hegemônica da racionalidade ocidental problematiza cinco formas de produção de não-existência: i) monocultura do saber e do rigor; ii) monocultura do tempo linear; iii) monocultura da naturalização das diferenças; iv) monocultura da escala dominante; e, v) monocultura dos critérios de produtividade capitalista.

\section{REFERÊNCIAS}

AIKENHEAD, G. S. Educación Ciencia-Tecnología-Sociedad (CTS): una buena idea como quiera que se le llame. Educación Química, México, v. 16, n. 2, p. 114-124, 2005.

ANDRADE, E. C. P.; CARVALHO, L. M. O pro-álcool e algumas relações CTS concebidas por alunos de 6 ạ série do ensino fundamental. Ciência \& Educação, Bauru-SP, v. 8, n. 2, p. 167-185, 2002. 
ensino de física em um curso técnico. Alexandria - Revista de Educação em Ciência e Tecnologia, Florianópolis - SC, v.5, n. 1, p. 33-61, mai. 2012.

AULER, D. Interações entre Ciência-Tecnologia-Sociedade no Contexto da Formação de Professores de Ciências. 2002. Tese (Doutorado em Educação), Centro de Educação, Universidade Federal de Santa Catarina, Florianópolis, 2002.

AULER, D.; DELIZOICOV D. Investigação de temas CTS no contexto do pensamento latino-americano. Revista Linhas Críticas, Brasília, DF, v.21, n.45, p. 275-296, mai./ago. 2015.

AULER, N. M. F. (Org.); AULER, D. (Org.). Concepção e execução de currículo no processo formativo de licenciandos do PIBID. 1ed. ed. CURITIBA: CRV, 2015. v. 1. $128 p$.

BERNARDO, J. R. da R.; VIANNA, D. M.; FONTOURA, H. A. da. Produção e consumo da energia elétrica: a construção de uma proposta baseada no enfoque ciênciatecnologia-sociedade- ambiente (CTSA). Ciência \& Ensino, Campinas - SP, v. 1, n. Especial, p. 1-12, nov. 2007.

CALLON, M. Des différentes formes de démocratie technique. Responsabilité \& Environnement, n. 9, p. 63-73, 1998.

CEREZO, J. A. L. Ciência, Tecnología y Sociedad: el estado de la cuestión em Europa y Estados Unidos. Revista Iberoamericana de Educación, n. 18, p. 125, sep-dic. 1998.

DAGNINO, R. A relação universidade-empresa no Brasil e o "argumento da hélice tríplice". Revista Brasileira de Inovação. v. 2. n. 2. Julho. Brasília, 2003.

DAGNINO, R. Uma estória sobre Ciência e Tecnologia, ou Começando pela extensão universitária... In: DAGNINO, R. (Org.). Estudos Sociais da Ciência e Tecnologia e Política de Ciência e Tecnologia: Alternativas para uma nova América Latina. Campina Grande: EDUEPB, 2010, p. 293-324.

DELIZOICOV; ANGOTTI, J. A.; PERNAMBUCO, M.M. Ensino de Ciências: fundamentos e métodos. São Paulo: Cortez, 2011.

FEENBERG, A. Marcuse ou Habermas: duas críticas da tecnologia. In: NEDER, R.(organizador): A Teoria Crítica de Andrew Feenberg. Brasília: Ed. CDS/OBMTS. 2010, p. 266. 
FREIRE, P. Pedagogia do oprimido. 48. ed. Rio de Janeiro: Paz e Terra, 2005.

FREIRE, P.; SHOR, I. Medo e ousadia: o cotidiano do professor. Rio de Janeiro: Paz e Terra, 1986.

FREITES, L.; GHEDIN, E. Pesquisas sobre estado da arte em CTS: análise comparativa com a produção em periódicos nacionais. Alexandria: Revista de Educação em Ciência e Tecnologia, Florianópolis, v.8, n.3, 2015.

GARCÍA, M. G.; CEREZO, J. A. L.; LÓPEZ, J. L. L. Ciencia, Tecnologia Y Sociedad: una introducción al estudio social de la Ciência y la tecnología. Madrid: Tecnos, 1996.

GIL, A. C. Métodos e Técnicas de Pesquisa Social. 6 ed. São Paulo: Atlas, 2008. 220p.

GÓMEZ, R. J. Progreso, determinismo y pesimismo tecnológico. Revista Redes, Argentina, v. 04, n. 10, p. 59-94, out 1997.

LOPES; CARVALHO. Possibilidades e Limitações da Prática do Professor na Experiência com a Temática Energia e Desenvolvimento Humano no Ensino de Ciências. Revista Brasileira de Pesquisa em Educação em Ciências, Belo Horizonte, v. 13, n. 2, 2013.

MORAES; GALIAZZI. Análise Textual Discursiva. Ijuí: Editora Unijuí, 2016.

SAMAGAIA, R. Comunicação, divulgação e educação científicas: Uma análise em função dos modelos teóricos e pedagógicos. Tese (Doutorado em Educação Científica e Tecnológica), Centro de Educação, Universidade Federal de Santa Catarina, Florianópolis, 2016.

SAMAGAIA, R.; PEDUZZI, L. O. Q. Uma experiência com o projeto Manhattan no ensino fundamental. Ciência \& Educação, Bauru - SP, v. 10, n. 2, p. 259-276, 2004.

SANTOS, M. A. Representações de comunicação pela ciência em educação (não) formal. Dissertação de Mestrado. (Mestrado em Ciências da Educação). Universidade de Aveiro, 2009. Abordagem CT-S (Ciência - Tecnologia - Sociedade) no Contexto da Educação Brasileira. Ensaio - Pesquisa em Educação em Ciências. v. 2, n. 2, dez. 2002. 
SOUSA SANTOS, B. de. Renovar a Teoria Crítica e Reinventar a Emancipação Social. São Paulo: Boitempo Editorial, 2007, 128 p.

\section{STRIEDER, R. Abordagem CTS na Educação Científica no Brasil: Sentidos e}

Perspectivas. 2011. Tese (Doutorado em Ensino de Ciências), Instituto de Física, Universidade de São Paulo, São Paulo, 2012.

STRIEDER, R.; BRAVO, B.; GIL QUILEZ, M.J. Las escalas local y global en el ámbito de la educación CTS de Brasil y España. Enseñanza de las Ciencias, n.o extraordinário, 2017.
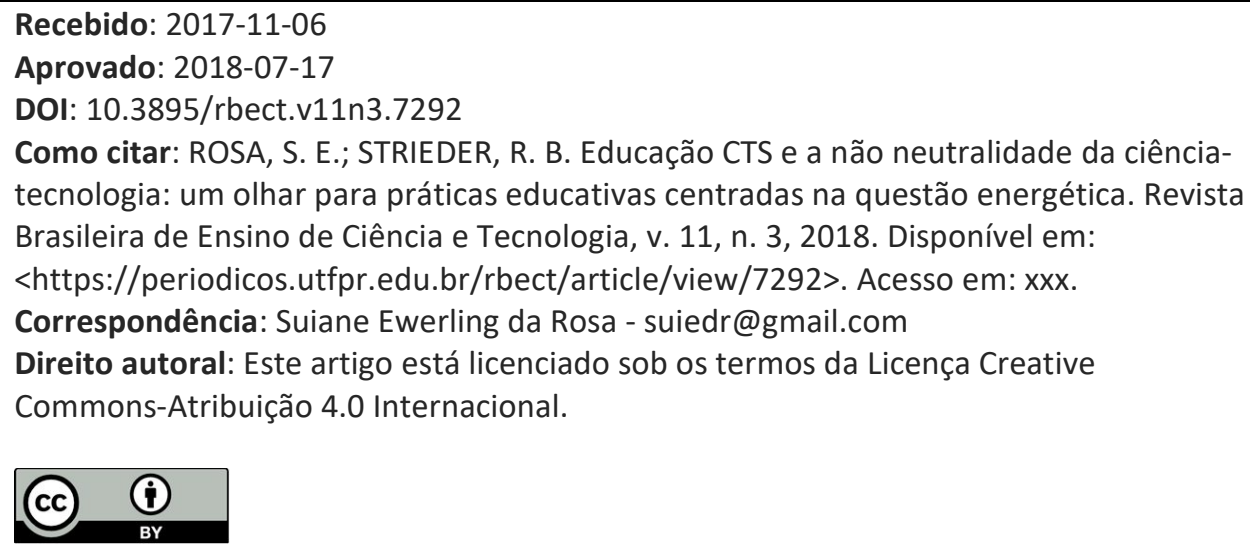